\title{
Communication in surgery: the therapy of hope
}

\author{
Laura A. Lambert \\ Department of Surgery, University of Utah, Huntsman Cancer Institute, Salt Lake City, UT, USA \\ Correspondence to: Laura A. Lambert. Department of Surgery, University of Utah, Huntsman Cancer Institute, Salt Lake City, UT, USA. \\ Email: laura.lambert@hci.utah.edu.
}

\begin{abstract}
Surgeons are frequently consulted for assistance in the palliative management of patients, and surgery is an essential tool in the armamentarium of comprehensive palliative care. Palliative surgical consults are some of the most challenging surgical consults, not only for technical reasons, but also because of the (usually) higher odds of morbidity or mortality, often in the setting of a limited life expectancy. Surgery is also often seen as the last possibility of hope, which can place a great emotional burden on the surgeon. Surgeons find themselves torn between concern about causing more harm than good, and not wanting to miss an opportunity to help. Although there is a growing body of literature around the outcomes for palliative surgery and patient selection, most palliative surgery decisions are still not evidence-based, but rather experienced-based. Because palliative surgical decision-making relies heavily on the surgeon's experience and risk (and/or regret) tolerance, surgeons often find themselves called upon to explain highly complex and nuanced concepts with existential outcomes to people who are desperate for hope. Even for the best communicators, achieving the goals of effective communication can be challenging in these situations, and in some instances, may seem unachievable. This article examines the communication challenges faced by surgeons in the palliative surgical setting and recommends specific strategies and approaches to help address those challenges and facilitate effective communication. Lastly, it considers the most necessary element of care for most patients and surgeons in the palliative setting: hope.
\end{abstract}

Keywords: Communication; hope; palliative; mindset; surgery; surgical palliative care

Submitted Dec 25, 2020. Accepted for publication Dec 13, 2021.

doi: $10.21037 /$ apm-20-2590

View this article at: https://dx.doi.org/10.21037/apm-20-2590

\section{The communication instrument in surgical care}

Effective communication is important for numerous reasons including physician and patient satisfaction, patient participation in care and adjustment to illness, malpractice liability, and important clinical markers of health (1). When doctors communicate well with their patients, clinical problems are identified more accurately, patients are more satisfied with their care, treatment plans are more likely to be followed, feelings of distress and vulnerability are lessened, and physicians' well-being is improved (2). For these reasons, communication is one of the most important instruments used by surgeons.

A primary expectation of surgical communication is the successful imparting of knowledge to patients and their families by the surgeon in a way that they will understand and that will help them make decisions. Many surgical situations can be successfully managed with straightforward information sharing: "The pain that brought you here tonight is a strangulated, incarcerated hernia, and the safest thing to do is surgery to fix the hernia". However, many situations, particularly in the palliative setting, do not lend themselves to straight-forward communication due to either technical, clinical, emotional, and/or philosophical complexity. These situations are usually also complicated by the goals, values and situational understanding of the patient and family, and the experience, values, and risktolerance of the surgeon. In these situations, delivering effective communication requires more of a procedure rather than just an instrument. 
Table 1 A comparison of the surgical and communication checklist

\begin{tabular}{|c|c|c|}
\hline Checklist Item & \multicolumn{2}{|c|}{ Description } \\
\hline I. Time & Book surgery for appropriate length of time & Schedule adequate protected time \\
\hline II. Background Information & Review clinical history, imaging, anatomy, goals & $\begin{array}{l}\text { Review clinical history, imaging, plans, } \\
\text { prognosis, goals if known }\end{array}$ \\
\hline IV. Assistance & $\begin{array}{l}\text { Surgical assistants, anesthesia provider, consulting } \\
\text { surgeon }\end{array}$ & $\begin{array}{l}\text { Appropriate family members, licensed social } \\
\text { worker, therapist, interpreter }\end{array}$ \\
\hline V. Time Out & $\begin{array}{l}\text { Confirm patient identity, allergies, antibiotics, special } \\
\text { needs, imaging, pathology, disposition }\end{array}$ & $\begin{array}{l}\text { Silence phone/pager, prepare opening line, } \\
\text { check own emotions }\end{array}$ \\
\hline
\end{tabular}

\section{The communication procedure in surgical care: preparatory phase}

Dr. Susan Block, Co-Director of the Harvard Medical School Center for Palliative Care, has said "A family meeting is a procedure, and it requires no less skill than performing an operation." (3). Dr. Geoffrey Dunn, a founding leader of surgical palliative care, said that "Delivering bad news is an invasive procedure that requires all of the thoughtfulness and skill required to perform a safe and competent operative procedure. The delivery of bad news and surgery both require an appropriate setting, assistance when indicated, patient permission, skillful execution, ongoing assessment of the impact of the intervention on the recipient and aftercare." (4). Similarly, in a talk on palliative care in surgical resident education at the American College of Surgeons Clinical Congress in 2003, Dr. Robert Milch stated "If you think about it, demonstration of competency in communication skills is much like performing an operation. We would never think of sending an untutored, un-mentored, unsupervised house officer into an operating room to do a procedure never seen, modeled, or performed before, and about which he had only read in a book." (5). As suggested by these statements, the good news about giving bad news is that effective communication is a skill that can be taught and learned, just like surgery, and is not just a gift or innate talent possessed by a lucky few. The knowledge, skills, and behaviors associated with effective communication can be learned and retained $(6,7)$.

During their training, surgeons learn the importance of considering and preparing for all possible eventualities before going to the operating room. The same approach can and should be used in a communication procedure. The definition of difficult—or "bad" news, as it is so often called, has become widely accepted to include any news that negatively alters another person's perception of their current situation or future (8). As it is impossible to know how another person will perceive the news until after the delivery, it is not unreasonable to consider every patient interaction as one with the potential to result in the delivery (or reception) of difficult news and to be ready and able to adapt as needed.

Checklists have been shown to improve outcomes in aviation and surgery and can also help with communication (9) (Table 1). First, just as a surgeon cannot do an operation without making time available for it, adequate protected time is needed to perform a communication procedure as well. Second, to provide optimal surgical care, the surgeon must gather the necessary information about the patient prior to recommending or scheduling a surgery. The same is true for effective communication. Although asking open-ended questions and allowing the patient to share what he or she understands is important, just as a good surgeon would not enter into a complex surgical operation without the necessary background information, neither does a good communicator enter into a complex surgical discussion without the necessary background information. Third, 
when planning a surgical operation, the surgeon needs to select and arrange for the proper setting-be it the clinic, the ambulatory center or the hospital operating room. The setting is equally as important for a communication procedure. Is it private? Are there enough chairs? Is it quiet? Is it convenient? Fourth, when planning for a surgery, the surgeon needs to ensure the availability of the necessary help and staff-a particular anesthesiologist, a certain surgical technologist, a qualified first assistant. In the setting of difficult communication, it may be necessary to have a licensed social worker, therapist, palliative care specialist or other involved physician and the appropriate family members or support persons present to help facilitate the discussion. Fifth, just as doing a "Surgical Time Out" before starting a surgery is helpful, so doing a "Communication Time Out" before starting a difficult discussion can be very helpful. The "Communication Time Out" should include reminders to silence phones and pagers, prepare the opening line, and reflect on personal emotions prior to starting the communication procedure. Sixth, as with a surgical procedure, the surgeon's position during a communication procedure is also important. The surgeon's eyes should be level with the patient's, which is usually best accomplished by sitting (7). Sitting is also helpful because it gives the impression of not being in a hurry and contributes to the perception that the surgeon has spent more time with the patient and family (10). Seventh, similar to prior to starting a surgery, all participants and their roles should be introduced and stated prior to starting the communication procedure. Finally, just as consent is required for a surgeon to operate on a patient, getting permission from the patient to proceed with the communication procedure not only allows the patient to brace for potentially bad news, but it can also signal the surgeon's understanding that this is a difficult, human situation. A simple demonstration of empathy such as this can help establish rapport between the surgeon and patient. Over the course of the encounter, as this rapport is nourished, the human connection itself becomes an essential source of hope for the patient and family-even in the setting of incurable disease.

\section{The communication techniques of surgical care: execution phase}

One of the original techniques described for effective palliative communication is the CLASS (Context, Listening, Acknowledgement, Strategy and Summary) technique. CLASS was first described by Robert Buckman in 2001 (7).
This model identifies 5 essential and crucial components of medical communication that are still relevant today: context (the physical context or setting), listening skills, acknowledgement of patient's emotions, strategy for clinical management, and summary. Within Context, which is essentially the preparatory phase of the technique, Buckman offers practical suggestions such as those described above -ensuring privacy for the patient, turning off background noise from radios or televisions, pulling a chair next to the patient and sitting down, ensuring that the patient knows who you are and what you do and maintaining eye contact when the patient is talking. For listening, Buckman suggests asking open questions, waiting for the patient to stop speaking before starting your next sentence, clarifying responses that are not understood and allowing the patient an opportunity to expand on statements.

One of the most daunting aspects of giving difficult or serious news is the anticipation and management of strong emotions. Acknowledgement refers to the validation and exploration of those emotions. Buckman counsels that "if strong emotions are not acknowledged in some way, the doctor will be perceived as insensitive and further attempts at communication will fail. The empathic response is a useful technique in an emotionally charged interview. It has nothing to do with a physician's personal feelings. The empathic response is a physician's acknowledgement of what the other person is experiencing. It is a technique showing the patient that you have observed the emotions he or she is experiencing." When responding to emotions, it is helpful to remember the mnemonics NURSE (Name, Understand, Respect, Support, Explore) (11) (Table 2) and SPIKES (Setting, Perception, Invitation, Knowledge, Emotion, Strategy), another technique designed by Buckman to further facilitate effective communication in emotionally charged situations (12) (Table 3). These techniques provide a cognitive approach that allows the surgeon to feel more comfortable being present with emotion. This is incredibly helpful, because rather than shying away from emotions, the surgeon can use them as an opportunity to explore the patient's true goals and values which can both facilitate and guide the challenging discussion and health care decisions. Often the most effective empathic responses follow the format of "I see that this is ..." or "it must be...". An appropriate example in surgery could be "it must be devastating for you to hear that your cancer has come back after such a long and difficult recovery from your surgery." Questions that further explore the emotions the patient is feeling can be "Tell me more about..." or "I wonder if... 
Table 2 NURSE-Respecting Emotions (Derived with permission from VitalTalk)

\begin{tabular}{lll}
\hline Action & Example & Expected result \\
\hline Name emotion & "It sounds like you are frustrated" & Decrease the intensity of the emotion \\
Seek understanding & "This helps me understand what you are thinking (feeling, worried about...)" & Increased dignity \\
Express respect & "I can see how strong you have been through all of this" & Increased resilience \\
Provide support & "I will do my best to make sure you have what you need" & Decreased fear of abandonment \\
Explore & "Could you say more about what you mean when you say that..." & Discover hope \\
\hline
\end{tabular}

Table 3 The SPIKES (Setting, Perception, Invitation, Knowledge, Emotions, Strategy)

\begin{tabular}{ll}
\hline Action & Example \\
\hline Setting up the interview & Ensure privacy; Make a connection; Limit interruptions; Invite necessary participants \\
Perception & $\begin{array}{l}\text { Assess the patient and family's perceptions; Identify knowledge, expectations and hope. Ask open-ended } \\
\text { questions-for example: what have you been told about your medical condition? What are you hoping for most? } \\
\text { Obtain the patient's invitation to discuss difficult or serious news and preferred type of information; Respect } \\
\text { patient's request to not receive information; Answer questions; Offer to speak to family member or other } \\
\text { representative } \\
\text { Match patient's level of language and comprehension; Use nontechnical words; Avoid excessive bluntness; Give } \\
\text { information in small amounts and check for understanding } \\
\text { Address emotions with empathic responses; Name the emotion to yourself; Connect the emotion to the cause; If } \\
\text { the cause is unclear, ask about it; Allow emotions to calm before proceeding } \\
\text { Emotions }\end{array} \quad \begin{array}{l}\text { Strategies provide hope and thereby lower anxiety; Shared decision-making establishes a relationship and allows } \\
\text { for shared responsibility for outcomes; Use other SPIKES steps as needed to discuss treatment plan }\end{array}$ \\
\hline
\end{tabular}

(e.g., your mom were here with us in this conversation, what would she have to say)...”. In addition to helping manage emotions, these simple exploratory questions can also provide insight into the patient's goals and values, nourish the rapport between the surgeon and patient, guide the discussion around treatment, identify areas for hope and ultimately lessen the potential for decisional regret and moral distress for the patient, family and surgeon.

For Strategy, Buckman states that "A reasonable management plan that the patient understands and will follow is better than an ideal plan that the patient will ignore". His recommendation that the physician consider what is best from a medical standpoint, assess the patient's expectations of the condition, treatment and outcome, then propose a strategy and assess the patient's response was the beginning of what is now known as shared decision-making (SDM). Over the past two decades, experts in the field of SDM have further refined this process to focus on eliciting patient goals and values and making recommendations that align with them (13). In the SDM model, clinicians provide patients with information about all the options and help them to identify their preferences in the context of their values - rather than emotional desires or "wants" (14). This approach can be particularly helpful to both patients and surgeons in the context of palliative surgery in which there is often little or no data to guide treatment recommendations and decisions. From an SDM perspective, surgeons can use statements that will help them partner with their patients such as "This is a really hard decision because we aren't sure what will happen if you choose option $\mathrm{x}$; let me show you how I think about this, and you can tell me whether it fits with what's important to you." (15).

Another approach that has been proposed by Taylor et al, specifically for surgeons in challenging clinical situations, is the Best Case/Worse Case (BC/WC) scenario planning (16). The aim of the BC/WC framework is to clarify the limits of what is possible so patients and families can manage uncertainty and prepare for poor outcomes. This approach uses narrative description and a handwritten graphic aid to illustrate choices between 


\section{surgery}

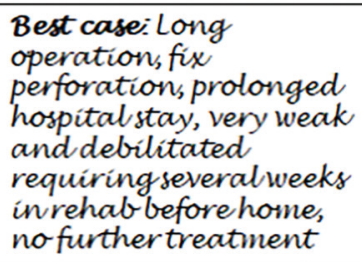

Most likely: Long operation, unabletofix perforation, prolonged intensive care unit stay, additional procedures, discharge to ventilator weaning facility and ongoingtreatment

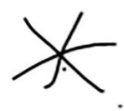

Worst case: Too unstable to complete definitive operation, never wakes up again, death in the operating room or in the intensive care unit over the corning days.

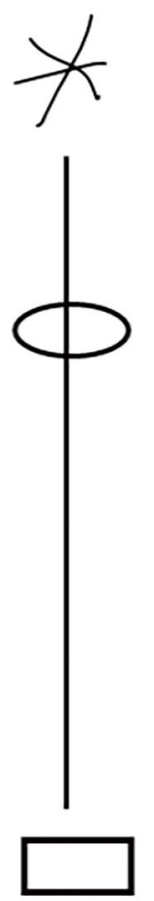

Best case: Symptoms well controlled with time to say goodbye with family, death in homerlike hospital room

\section{Most likely:}

Symptorns well controlled butless coherent, some tume with family, death in ICU

Figure 1 Example of a Best Case/Worst Case graphic aid that the surgeon would create and use during a decision-making discussion for a patient with a serious surgical problem. The box represents the worst case scenario, the star represents the best case scenario, and the oval indicates the most likely outcome (16). ICU, intensive care unit.

treatments and engage patients and families (Figure 1). The scenarios used allow patients and families to explore possible futures and see the course from the current situation to the future outcome. Using such scenarios, patients and families gain a new way of seeing beyond their immediate "needs", can incorporate their goals and values, and thereby think strategically and make decisions based on what is most important to them (16).

This approach can be particularly helpful in communication with patients who are facing their own mortality and families who are not ready to let go. In these scenarios, the smallest amount of hope that surgery offers can make even the most daunting risks seem worth taking. Under the guise of "full disclosure" and" informed consent", surgeons often try to paint as bleak a picture as possible for the patient and family, in an effort to dissuade the patient from choosing surgery. When, despite these efforts, the patient and family ask for surgery, some surgeons see this as a contract that the patient and family agree to "endure to the end", including any additional interventions that may be required—additional procedures, feeding tubes, tracheostomy, dialysis, rehabilitation etc. (17). There is often a sense of frustration and betrayal on the part of the surgeon when, within a few days after the index surgery, the family decides to stop any further life-prolonging care. Because surgical professionalism demands that the surgeon make a sincere effort to understand and be understanding of the perspective of the patient and family-without expectation of the same in return-surgeons in this setting are at risk of experiencing moral distress. Using the $\mathrm{BC} / \mathrm{WC}$ scenarios, preoperative advance care planning, including explicit discussion and agreement on the extent or limitations on postoperative care, often including a time-limited trial defined by specific goal-concordant outcome, can be achieved. For these reasons, understanding the perspective of the patient and family is critical for both the outcome of 

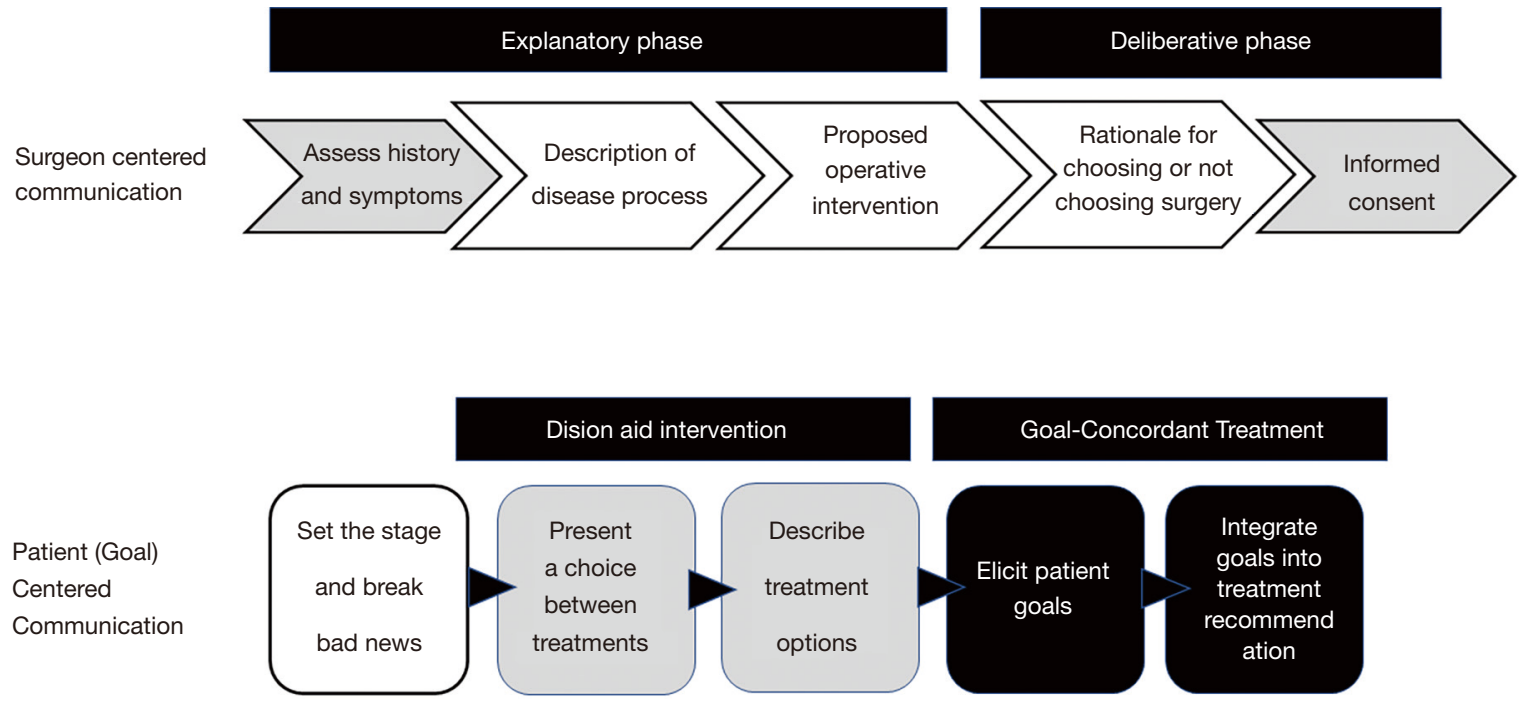

Figure 2 Inward (surgeon-centered) and outward (patient-centered) communication (19-21).

the encounter and the surgeon's well-being.

Finally, for the Summary part of the original CLASS approach, Buckman makes the following recommendations: (I) end the interview with a summary of the main topics that have been discussed, (II) offer to answer questions or discuss uncovered topics, (III) plan for the time, place, and context of next contact and, most importantly, (IV) do not make promises that you cannot keep.

\section{The communication triangle}

Another communication technique known as the Palliative Triangle was introduced in 2009 by Miner et al. as a tool to help (I) communication between patients, families and surgeons, (II) identify the goals of care and hopes of all three parties, and (III) improve patient selection for palliative surgery (18) (Figure 2) Through the dynamics of the triangle, the patient's complaints, values and emotional support are taken into account while weighing the medical and surgical alternatives. Like the $\mathrm{BC} / \mathrm{WC}$ scenario approach to SDM, the Palliative Triangle also offers an opportunity to learn about and address a patient's and/or family's expectations regarding the intent of the proposed procedure, helping to moderate any incongruent expectations between surgeon, patient and family members. Interestingly, in 2002, Miner et al demonstrated that by leveraging the strength of a 'critical triangle of interaction' (the predecessor of the Palliative Triangle) between patient, family and surgeon, patients who underwent palliative surgery were more satisfied with their situation even if their symptoms were not palliated (22). In 2011, another study by Miner et al suggested that use of the Palliative Triangle helped improve patient selection and was associated with significantly better symptom resolution, fewer postoperative complications compared with previously published results, and greater patient satisfaction toward the surgeon. The authors postulated that it was the building of a strong relationship between the surgeon, patient and family that lead to the high patient satisfaction toward the surgeon after palliative operation - even if there was no demonstrable benefit (23).

In a triangular model, what impacts one point necessarily impacts the other two- and the Palliative Triangle is no exception. Although Miner et al did not comment on surgeon satisfaction in the study, it is reasonable to assume that surgeon satisfaction will be impacted by the patient's perception of the outcome. This is important because anticipatory regret has been shown to play a significant role in medical decision-making, with surgeons tending to regret errors of omission more than commission (24). Similarly, despite seemingly well-executed SDM, patients can experience decisional regret due to either the outcome of the treatment, the treatment option decided upon or the process by which they came to their decision (25). While the surgeon may have little or no control over the first two factors (the outcome or the patient's ultimate treatment decision), he or she does play a significant role in the process by which the decision was made. Although there is no published data on the impact of patient decisional regret 
on surgeon regret, it is reasonable to expect more surgeon regret if there is more patient regret. Thus, one way to minimize potential regret by all parties is for the surgeon to ensure good communication, relationship building, assessment of the patient's desired level of involvement in the decision-making process and incorporation of the patient's goals and values in the decision-making process.

\section{The communication mindset}

Giving difficult or serious news is challenging for a number of reasons-fear of emotions, fear of taking away hope, the feeling of being helpless, fear of making a mistake, and fear of rejection. In addition, many surgeons have never had any real training in how to give serious or sad news. Surgeons often face additional challenges with the news that they must deliver. These challenges can be related to both surgeon and patient factors. Some of the surgeon/surgical factors include the complex nature of the procedures that are involved, often created by complex pathophysiology occurring in the setting of a complex clinical course with a high risk of complications (for which only the surgeon knows the true burden of personal responsibility assumed once an incision is made). Patient factors can include fear of the unknown, hopelessness, loss of control, fear of abandonment/isolation, pain (physical, emotional, spiritual) and a sense of a loss of dignity.

Another reason why giving difficult news is challenging is due to what Dr. Susan Block describes as a basic conceptual mistake. "For doctors, the primary purpose of a discussion about terminal illness is to determine what people wantwhether they want chemo (surgery) or not, whether they want to be resuscitated or not, whether they want hospice or not. They focus on laying out the facts and the options. But that's a mistake. A large part of the task is helping people negotiate the overwhelming anxiety-anxiety about death, anxiety about suffering, anxiety about loved ones, anxiety about finances". The key, she says, to overcoming this challenge is making the patient and his or her values the center of the communication (3). As previously discussed, focusing on the patient's values, rather than wants, can completely reshape the conversation and influence the ultimate outcome (14).

Essentially, there are two ways or mindsets by which the surgeon can approach these difficult conversations: (I) an inward or surgeon-centered approach or (II) an outward or patient-centered approach. In inward (surgeon-centered) communication, the surgeon essentially tells the patient what the problem is and then tells the patient what can or cannot be done to fix it (Figure 2). The "fix-it" approach to medical decisions was described in 1991 as a decision making framework that presumes the role of health care is to provide medical interventions that restore normalcy in the face of any aberration from normal form or function, thereby fixing the problem (26). The concept of fixing an acute abnormality with return to normalcy is especially familiar to surgeons. However, according to a study by Kruser et al., surgeons need to be aware that focus on fixing an isolated problem may lead both the surgeon and patient quickly down the path of intervention on an isolated issue, without adequate consideration of alternative treatment options, the broader context of the patient's situation or what the patient values (19). In this study, the authors found that during preoperative discussions about high risk procedures by surgeons who were considered excellent communicators, the majority used the "fix-it" approach (i.e., "this is what is 'broken' and this is what needs to be done to restore normalcy") to explain the clinical situation and potential surgical interventions to the patients. Interestingly, most did not use the "fix-it" approach when providing a rationale for or against proceeding with surgery. The authors also noted that the discussions were dominated by the surgeon. Despite this, and although follow-up with the patients was not part of the study, the authors raised concerns that when surgeons explain complex medical/ surgical problem to patients from a "fix-it" approach, even if they directly state that the problem may not be fixable or that "fixing" the problem may not be effective during the deliberation phase, patients may stay focused on the desire to be fixed and will choose to proceed with "the fix" (surgery) regardless of the potential risks or unlikelihood of success (return to normalcy). Consequently, they advocate for an outward or patient-centered approach such as using more narrative based techniques, like the BC/WC scenarios and the Palliative Triangle, in which the patient's goals and values and multiple alternate treatments and outcomes are considered,

However, in order for a surgeon to effectively influence the behavior of the patient and the family in an efficient and professional manner, his or her mindset, e.g., how he or she sees others, is essential. The Arbinger Influence Pyramid is a proven leadership approach to influencing behavior which is readily applicable to patient-family-surgeon interactions $(20,21)$ (Figure 3). Foundational to the success of using the Influence Pyramid approach is that the surgeon must adjust his or her "mindset" to an "outward mindset" 


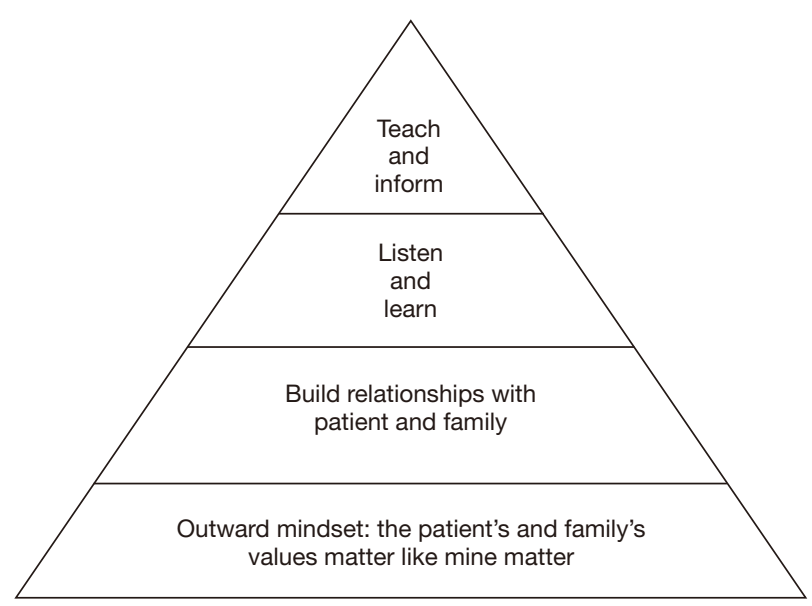

Figure 3 The Arbinger Influence Pyramid ${ }^{\mathrm{TM}}$. The Influence Pyramid is a proven framework designed to help influence behavior and improve results beginning with a shift in mindset. Used with the permission of and adapted from The Arbinger Institute, The Anatomy of Peace - Resolving the Heart of Conflict, 2015, Berrett-Koehler Publishers, Inc. and The Arbinger Institute, The Outward Mindset-Seeing Beyond Ourselves, 2016 Berrett-Koehler Publishers, Inc. Reprinted with permission.

through which the surgeon sees patients as people and not as problems to be fixed. From this mindset, the goals and values of the patient and family become an essential aspect of any solution to the problem. An outward mindset will also lead the surgeon to become naturally curious about what the patient knows and what is most important to the patient and family. It also fosters listening with real intent to understand what matters most to the patient and family. According to Dr. Block, a simple rule of thumb is that "if (the surgeon is) talking more than half of the time, (the surgeon is) talking too much" (3). The next step in outward (patient-centered) communication and on the Influence Pyramid is to provide information. Again, from an outward mindset, the surgeon will naturally care about doing this in the best manner possible for the patientse.g., by giving the information in small quantities, and using appropriate language and pictures. The surgeon will also assess the patient's and family's reaction and understanding of the information provided, give them time to process what they have heard and correct any misunderstanding. One of the most common concerns about the outward, patient-centered approach is the amount of time it requires. However, this approach can actually save time in the long run and make a difficult situation easier for the surgeon, the patient and family (27). Furthermore, without the right mindset, any technique used, regardless of efficiency, will be less effective.

Another concern driving surgeon communication practices is the anticipatory fear of strong emotions. Although emotions can offer the surgeon an opportunity to explore the patient's goals and values, emotions that express suffering are hard to bear and often compel us to some sort of action. When anticipating strong emotions, it can be helpful to provide a "warning shot" ("Unfortunately, the operation was not as successful as we were hoping") to allow the patient and family to brace themselves emotionally. Crying presents a particular challenge because it usually stops the conversation. Compelled to do something, the natural reaction is to start talking while the patient is still crying, which, according to Buckman is unproductive, as "(the surgeon) will be perceived as insensitive and further attempts at communication will fail" (7). The recommended course of action is to first remember that, as observed by Dr. Anthony Back, "all crying stops eventually" (Personal communication, OncoTalk, 2015). Most patients do not want to cry in front of their surgeon and most will try to stop crying as quickly as possible. The immediate best course of action is usually no action. Be patient. Be quiet. Allow silence. Bear witness. Have tissues available and within reach. Once the crying stops, the NURSE and SPIKES techniques (Tables 2,3) are helpful to resume the conversation and address and explore the emotions as described above. However, if the situation is too emotional, the meeting may need to be postponed and the patient should be offered referral to someone who can provide the appropriate emotional, psychological or spiritual support.

\section{The communication consultation}

There are times in both surgery and communication when it is appropriate and beneficial to request help from another provider with specific expertise or a different perspective. Initiation of a palliative surgery consultation may be an appropriate time for initiating a specialty palliative care consultation as well, if available. While some surgeons and patients view a palliative care consult as "giving up", this could not be further from the truth. Unlike hospice (which is a medical insurance benefit that requires a life expectancy of less than six months if the life-threatening disease is untreated and the patient forgoes disease-directed treatment), all patients with symptoms from a serious illness 
or its treatment stand to benefit from palliative care. While most patients' symptoms can be adequately palliated by their primary physician (either their primary care provider or primary specialist), advanced, life-threatening illnesses, such as cancer and trauma, can pose additional challenges in terms of physical, emotional, psychological, spiritual and social symptomatology. It is preferable to initiate a palliative care consultation before these symptoms become unmanageable, as this will reduce the perceived implication of "giving up" when there is an acute need for the expertise of a specialized palliative care provider.

Palliative care consultation can also help take some of the burden off the primary specialist for conducting the harder conversations around goals of care and advanced directives and allowing the specialist to focus on the plan of treatment. Having these difficult conversations early is essential for the comprehensive management of lifethreatening illness and should not be avoided due to provider unease and other perceived barriers (28). There is usually little hesitation to refer a patient to a surgical or medical specialist for a medical indication. The same should be true when there is a palliative care indication-including complex communication. Furthermore, it has been shown that patients who understand their poorer prognosis near the end of life are less likely to choose invasive treatments that can prolong suffering and time away from home (29-31). Other studies have shown that early initiation of palliative care in patients with advanced cancer can improve overall survival despite patients receiving less cancer-directed therapy (32). A palliative care consultant who is an expert in communication can provide invaluable help with this aspect of the patient's care.

\section{Communication-based therapy of hope}

Both inside and outside of the operating room, effective communication is essential for successful surgical patient outcomes. As described in this article, 3 main purposes of communication in patient-surgeon interactions are (I) to inform, (II) to create a trusting relationship and (III) to provide hope-for both the patient and the surgeon. In addition to the independent importance of these three purposes, each one is vital to the other two. How the surgeon imparts and receives information establishes the foundation of the relationship with the patient and family which allows for the development of the trust that is essential to a successful and synergistic patient-surgeon relationship. Once established, this synergistic relationship then becomes its own form of therapy for both patients, families and surgeons - the therapy of hope, just when it seems all hope is lost. Hope is essential for livingespecially in the setting of incurable disease. Even when there is no hope of prolonging survival or a return to normalcy, there are other things for which one can hoperelief frompain, relief fromstress for a loved one, a plan for those left behind, more dignity, not being abandoned. Helping patients and their families find other sources of hope can be as therapeutic as oxygen is for the treatment of hypoxia. For most patients, when the surgeon says "there is nothing more I can do", it is like all the oxygen has been sucked out of the room. It is at this point that the surgeon's presence becomes therapeutic-the impact of which is delivered through attendance and thoughtful communication. Communication skills and techniques, like those described in this article, can be taught, learned and retained. But like any skill or behavior, communication skills can be performed from either an inward (surgeoncentered) mindset, or an outward (patient-centered) mindset. From an outward mindset, when the surgeon truly sees the patient and their families as people rather than problems, the patient-centered communication procedure will happen more naturally. From an outward mindset, the surgeon will explore and discover what is most important to the patient and family, and more options for hope will become available. From an outward mindset, healing will be promoted and living, even in the face of incurable disease, will be sustained. From an outward mindset, moral distress can be avoided. In the immortal words of the poet Maya Angelou, "I've learned that people will forget what you said, people will forget what you did, but people will never forget how you made them feel." In this way, the communicationbased therapy of hope can benefit patients, families and surgeons alike.

\section{Acknowledgments}

The author would like to thank Dr. Ana Berlin for her editorial guidance and support.

Funding: None.

\section{Footnote}

Provenance and Peer Review: This article was commissioned by the editorial office, Annals of Palliative Medicine for the series "Palliative Care and Surgery". The article has undergone external peer review. 
Conflicts of Interest: The author has completed the ICMJE uniform disclosure form (available at https://apm. amegroups.com/article/view/10.21037/apm-20-2590/coif). The series "Palliative Care and Surgery" was commissioned by the editorial office without any funding or sponsorship. The author has no other conflicts of interest to declare.

Ethical Statement: The author is accountable for all aspects of the work in ensuring that questions related to the accuracy or integrity of any part of the work are appropriately investigated and resolved.

Open Access Statement: This is an Open Access article distributed in accordance with the Creative Commons Attribution-NonCommercial-NoDerivs 4.0 International License (CC BY-NC-ND 4.0), which permits the noncommercial replication and distribution of the article with the strict proviso that no changes or edits are made and the original work is properly cited (including links to both the formal publication through the relevant DOI and the license). See: https://creativecommons.org/licenses/by-nc-nd/4.0/.

\section{References}

1. Miner TJ. Communication skills in palliative surgery: skill and effort are key. Surg Clin North Am 2011;91:355-66, ix.

2. Maguire P, Pitceathly C. Key communication skills and how to acquire them. BMJ 2002;325:697-700.

3. Gawande A. Letting Go. Annals of Medicine The New Yorker. 2010. Available online: http://irasilver.org/wpcontent/uploads/2011/08/Reading-Letting-go-Gawande.pdf

4. Surgeons ACo. Surgical Palliative Care: A Resident's Guide 2009. Available online: https://www.facs.org/ /media/files/ education/palliativecare/surgicalpalliativecareresidents.ashx.

5. McCahill LE, Dunn GP, Mosenthal AC, et al. Palliation as a core surgical principle: part 1. J Am Coll Surg 2004;199:149-60.

6. Milch RA, Dunn GP. Communication: part of the surgical armamentarium. J Am Coll Surg 2001;193:449-51.

7. Buckman R. Communication skills in palliative care: a practical guide. Neurol Clin 2001;19:989-1004.

8. Eggly S, Penner L, Albrecht TL, et al. Discussing bad news in the outpatient oncology clinic: rethinking current communication guidelines. J Clin Oncol 2006;24:716-9.

9. Haynes AB, Weiser TG, Berry WR, et al. A surgical safety checklist to reduce morbidity and mortality in a global population. N Engl J Med 2009;360:491-9.

10. Swayden KJ, Anderson KK, Connelly LM, et al. Effect of sitting vs. standing on perception of provider time at bedside: a pilot study. Patient Educ Couns 2012;86:166-71.

11. VitalTalk. Responding to Emotion: Respecting 2019. Available online: https://www.vitaltalk.org/guides/ responding-to-emotion-respecting/.

12. Baile WF, Buckman R, Lenzi R, et al. SPIKES-A six-step protocol for delivering bad news: application to the patient with cancer. Oncologist 2000;5:302-11.

13. Elwyn G, Laitner S, Coulter A, et al. Implementing shared decision making in the NHS. BMJ 2010;341:c5146.

14. Schwarze ML, Campbell TC, Cunningham TV, et al. You Can't Get What You Want: Innovation for End-of-Life Communication in the Intensive Care Unit. Am J Respir Crit Care Med 2016;193:14-6.

15. Fried TR. Shared Decision Making--Finding the Sweet Spot. N Engl J Med 2016;374:104-6.

16. Taylor LJ, Nabozny MJ, Steffens NM, et al. A Framework to Improve Surgeon Communication in High-Stakes Surgical Decisions: Best Case/Worst Case. JAMA Surg 2017;152:531-8.

17. Schwarze ML, Redmann AJ, Alexander GC, et al. Surgeons expect patients to buy-in to postoperative life support preoperatively: results of a national survey. Crit Care Med 2013;41:1-8.

18. Thomay AA, Jaques DP, Miner TJ. Surgical palliation: getting back to our roots. Surg Clin North Am 2009;89:27-41, vii-viii.

19. Kruser JM, Pecanac KE, Brasel KJ, et al. "And I think that we can fix it": mental models used in high-risk surgical decision making. Ann Surg 2015;261:678-84.

20. The Arbinger Institute.. The Anatomy of Peace- Resolving the Heart of Conflict. Oakland, CA: Berrett-Koehler Publishers, Inc; 2015.

21. The Arbinger Institute.. The Outward Mindset - Seeing Beyond Ourselves. Oakland, CA: Berrett-Koehler Publishers, Inc; 2016.

22. Miner TJ, Jaques DP, Shriver CD. A prospective evaluation of patients undergoing surgery for the palliation of an advanced malignancy. Ann Surg Oncol 2002;9:696-703.

23. Miner TJ, Cohen J, Charpentier K, et al. The palliative triangle: improved patient selection and outcomes associated with palliative operations. Arch Surg 2011;146:517-22.

24. Wilson A, Ronnekleiv-Kelly SM, Pawlik TM. Regret in Surgical Decision Making: A Systematic Review of Patient and Physician Perspectives. World J Surg 2017;41:1454-65.

25. Selby LV, Aquina CT, Pawlik TM. When a Patient Regrets Having Undergone a Carefully and Jointly Considered 
Treatment Plan, How Should Her Physician Respond? AMA J Ethics 2020;22:E352-357.

26. Lynn J, DeGrazia D. An outcomes model of medical decision making. Theor Med 1991;12:325-43.

27. Tongue JR, Epps HR, Forese LL. Communication skills. Instr Course Lect 2005;54:3-9.

28. Suwanabol PA, Reichstein AC, Suzer-Gurtekin ZT, et al. Surgeons' Perceived Barriers to Palliative and End-ofLife Care: A Mixed Methods Study of a Surgical Society. J Palliat Med 2018;21:780-8.

29. Mack JW, Weeks JC, Wright AA, et al. End-of-life discussions, goal attainment, and distress at the end of life: predictors and outcomes of receipt of care consistent with preferences. J Clin Oncol 2010;28:1203-8.

30. Weeks JC, Cook EF, O'Day SJ, et al. Relationship between cancer patients' predictions of prognosis and their treatment preferences. JAMA 1998;279:1709-14.

31. Zhang B, Nilsson ME, Prigerson HG. Factors important to patients' quality of life at the end of life. Arch Intern Med 2012;172:1133-42.

32. Temel JS, Greer JA, Muzikansky A, et al. Early palliative care for patients with metastatic non-small-cell lung cancer. N Engl J Med 2010;363:733-42.

Cite this article as: Lambert LA. Communication in surgery: the therapy of hope. Ann Palliat Med 2022;11(2):958-968. doi: 10.21037/apm-20-2590 